\title{
Betel-quid use and its effects on symptoms of schizophrenia and extrapyramidal symptoms among a group of patients in a tertiary care hospital in Sri Lanka \\ A Isuru, D Ediriweera, A Pathmeswaran, A Embuldeniya, H Narammalage, S Warnakulasuriya, KALA Kuruppuarachchi, A Hapangama
}

\section{Abstract \\ Background}

There is limited research regarding the prevalence of betel quid use and its effects on symptoms of patients with schizophrenia. Available studies suggest an association between betel chewing and positive symptoms among males with schizophrenia.

\section{Aims}

This study aimed to compare the prevalence of betel quid chewing between patients with and without mental illness, and to explore the association between betel quid use, symptoms of schizophrenia and side effects of psychotropic medication.

\section{Methods}

A cross sectional descriptive study was carried at outpatient clinics at a tertiary care hospital in Sri Lanka. A structured interview schedule was administered to all participants.

\section{Results}

Out of 1000 participants, $20.9 \%$ chewed betel quid
(95\% Cl: $18.4 \%-23.4 \%)$. The rate of betel chewing among patients with and without a mental illness was $20.7 \%$ (95\% Cl: $17.0 \%-24.4 \%)$ and $21.0 \%$ (95\% Cl: $17.6 \%-24.5 \%)$ respectively and there was no significant difference between the two groups. There was no statistically significant difference between the occurrence of positive or negative symptoms and extrapyramidal side effects in patients with schizophrenia who did and did not chew betel. Female gender $(p=0.004)$ and betel quid chewing (0.002) were associated with more anticholinergic side effects.

\section{Conclusions}

There was no association between betel quid usage and the occurrence of positive or negative symptoms of schizophrenia or extrapyramidal side effects.

Key words: schizophrenia, betel quid, positive symptoms, negative symptoms, extrapyramidal side effects.

SL J Psychiatry 2020; 11(1): 32-38

\section{Background}

Betel consumption has been traditionally associated with cultural practices in South Asian, South East Asian and Asian Pacific regions $(1,2)$. Betel is chewed either alone or more often as a quid with additives such as areca nut, slaked lime, tobacco, cloves, or cardamom. The ingredients and preparation of the betel quid may vary from region to region. In Sri Lanka betel leaf (Piper betle) is usually consumed in a quid of varied combinations with ingredients such as slaked lime, tobacco, areca nut (Areca catechu) (3). Areca nut is the primary ingredient in the quid and chewing tobacco may or may not be added according to preference.
Population based rural and urban surveys in Pakistan and India conducted during the last twenty-five years, report that $20-40 \%$ of the population aged fifteen years and over were betel quid or areca nut chewers (2). A prevalence study conducted in 1995 in Palau reported that $72 \%$ of the males and $80 \%$ of the females chewed betel quid, and of these, $80 \%$ had incorporated tobacco in their quid (4). According to the National Oral Health Survey of 1994-1995 carried out in Sri Lanka, the prevalence of betel chewing was $40.5 \%$ among those aged between $35-74$ years, while it was $33.78 \%$, among those between the aged 35-44 years (5). Another study among the villagers in the Central Province of Sri Lanka 
reported that $54 \%$ of males and $42 \%$ of females used betel quid regularly (6). A 2007 study in two districts in Sri Lanka reported a marked difference in the prevalence of betel quid chewing between urban and rural populations $-17.6 \%$ and $1.7 \%$ in the rural and urban district, respectively (7).

An Indian study on the prevalence of areca nut use among psychiatric patients showed that $24 \%$ of the study sample had recent use and $10 \%$ had dependence (8). However, prevalence studies related to betel quid and areca nut use among mentally ill patients in Sri Lanka are sparse. A preliminary study conducted at North Colombo Teaching Hospital, Ragama, reported that a higher proportion of patients with schizophrenia chewed betel compared with control subjects (9).

Burton-Bradley first referred to the psychotropic effects of areca nut among chronic users in Papua New Guinea (10). Research on patients with mental illness and areca nut or betel quid use has been mainly in relation to patients with schizophrenia $(11,12)$. Research evidence supports the high prevalence of betel chewing amongst patients with schizophrenia compared to the normal population (11). Sullivan et al, in 2007 suggested a therapeutic relationship between areca chewing and positive symptoms among male schizophrenic patients in Palau, but could not demonstrate an association between betel use and extrapyramidal symptoms (11). Some authors suggest that patients with schizophrenia chew betel as a measure to self-medicate their symptoms, but there is also increasing research evidence contradicting the self-medication hypothesis $(11,13)$. On the other hand, arecoline, which is an ingredient of the areca nut, is a potent muscarinic receptor agonist. Recent neurobiological research hypothesizes the possible mechanisms involving muscarinic receptors in the causation of some of the symptoms of schizophrenia (13). Therefore, it is important to understand the basis of the association between schizophrenia and betel chewing, which may have therapeutic and etiological implications with regards to this disorder. This study aimed to compare the prevalence of betel quid chewing between patients with and without mental illness, and to explore the association between betel quid use, symptoms of schizophrenia and side effects of psychotropic medication.

\section{Methods}

\section{Study design}

This was carried as a cross sectional study, conducted from January 2014 to December 2014.

\section{Sample}

Patients attending medical, surgical and psychiatry outpatient clinics of North Colombo Teaching Hospital during the study period, who were aged 18 years and over, were considered eligible for inclusion in the study. Patients who were less than 18 years of age, who were grossly psychotic or severely physically ill were excluded.

\section{Outcome measures and tools used in the study}

A structured interview schedule administered to all participants, by an interviewer conversant in all three languages (Sinhalese, Tamil and English), was used to gather demographic data, and factors related to medical, surgical illness, and substance use. The psychiatric diagnoses of patients recruited from the psychiatry outpatient clinics were confirmed by perusal of patient diagnoses cards and/or by a clinical interview conducted by a consultant psychiatrist based on ICD 10 criteria. In patients diagnosed to have schizophrenia, the Positive and Negative Syndrome Scale (PANSS) and the Liverpool University Neuroleptic Side Effect Rating Scale (LUNCERS) were used to measure symptoms of schizophrenia and the side effects due to psychotropic respectively $(15,16)$.

\section{Quantification of the amount of betel used}

During the interviewer-conducted structured interview schedule, participants were asked regarding the number of betel quid they chewed per day. They were also asked to show how much areca was included per quid using a betel/areca tray made available to them during the interviews and the amount chosen by each subject was weighed.

\section{Ethics}

All participants were provided information about the study. Only those who gave written informed consent were included in the study. Ethical approval for the study was granted by Ethical Review Committee, University of Kelaniya, Sri Lanka.

\section{Analysis}

Demographic data were summarized using means with standard deviations and counts with percentages. The prevalence of betel quid chewing was estimated for the whole study sample, as well as for those with and without mental illness. Group comparisons were done using the two-sample t test. Linear models were used to investigate the variables associated with EPSE and anticholinergic side effects. A p value of 0.05 was considered as significant. R programming language version 3.5.1 was used for the analysis. 


\section{Results}

A total of 1,000 patients attending outpatient clinics in the North Colombo Teaching Hospital, Sri Lanka, were included in the study, of whom 502 (50.3\%) were attending medical clinics, 462 (46.2\%) were attending psychiatry clinics and 35 (3.5\%) surgical clinics. Of the total study sample $410(41.0 \%)$ were males (Table 1$)$. The diagnoses of patients recruited from the psychiatry clinic included schizophrenia, schizoaffective disorder, bipolar affective disorder, depression, cannabis induced psychosis, and alcohol use disorders. Of the total study participants, 209 (20.9\%) chewed betel quid (95\% CI: 18.4\% - 23.4\%). The rate of betel quid use was $20.7 \%$ (95\% CI: $17.0 \%$ $24.4 \%$ ) among patients with mental illnesses and $21.0 \%$ (95\% CI: $17.6 \%$ - 24.5\%) among other patients who were attending medical or surgical clinics. There was no significant difference in the prevalence of betel quid chewing between those with and without mental illnesses.
Betel quid chewing was reported among 38 (80.9\%) of the males with a diagnosis of schizophrenia $(\mathrm{p}<0.01)$. There was no significant difference in the total positive, negative scores or total scores of the PANSS, in patients with schizophrenia who did and did not chew betel quid (Figure 1, Table 2). Betel quid chewers with schizophrenia had more anticholinergic side effects $(p=0.04)$ compared to those patients with schizophrenia who did not chew betel quid.

According to the fitted models, in participants with schizophrenia, only the age of patients showed a significant association with extra pyramidal side effects (EPSE). Increasing age was associated with higher scores when EPSE were assessed using the LUNCERS ( $p=0.025)$. Anticholinergic side effects were significantly associated with female gender $(\mathrm{p}=0.004)$ and betel chewing $(0.002)$ (Table 3).

\begin{tabular}{|c|c|c|c|}
\hline & $\begin{array}{l}\text { Psychiatric patients } \\
\qquad(n=463)\end{array}$ & $\begin{array}{l}\text { Non-psychiatric } \\
\text { patients }(n=537)\end{array}$ & $P$ value \\
\hline Mean age (SD) & $45.1(13.7)$ & $60.5(13.4)$ & $<0.001$ \\
\hline Males (\%) & $310(57.5)$ & $227(42.3)$ & 0.414 \\
\hline \multicolumn{4}{|l|}{ Educational level } \\
\hline Primary & $44(9.7)$ & $98(18.7)$ & $<0.001$ \\
\hline Secondary & $312(68.7)$ & $356(67.8)$ & \\
\hline Tertiary & $98(21.6)$ & $71(13.5)$ & \\
\hline Employed (\%) & $181(39.2)$ & $275(51.4)$ & $<0.001$ \\
\hline \multicolumn{4}{|l|}{ Marital status } \\
\hline Single & $156(33.7)$ & $32(6.0)$ & $<0.001$ \\
\hline Married & $293(63.3)$ & $505(94.0)$ & \\
\hline Separated/Divorced & $14(3.0)$ & $0(0.0)$ & \\
\hline \multicolumn{4}{|l|}{ Living status } \\
\hline Own/relatives home & $453(98.1)$ & $526(98.7)$ & 0.299 \\
\hline Residential home & $3(0.6)$ & $0(0.0)$ & \\
\hline Homeless & $6(1.3)$ & $7(1.3)$ & \\
\hline \multicolumn{4}{|l|}{ Betel quid use } \\
\hline Yes & $96(20.7)$ & $113(21.0)$ & 0.967 \\
\hline No & $367(79.3)$ & $424(79.0)$ & \\
\hline 1-5 quids/day & $77(80.2)$ & $99(84.2)$ & 0.373 \\
\hline 6-10 quids/day & $14(14.6)$ & $16(14.0)$ & \\
\hline $10+$ quids/day & $5(5.2)$ & $2(1.8)$ & \\
\hline
\end{tabular}


a) Total Negative score

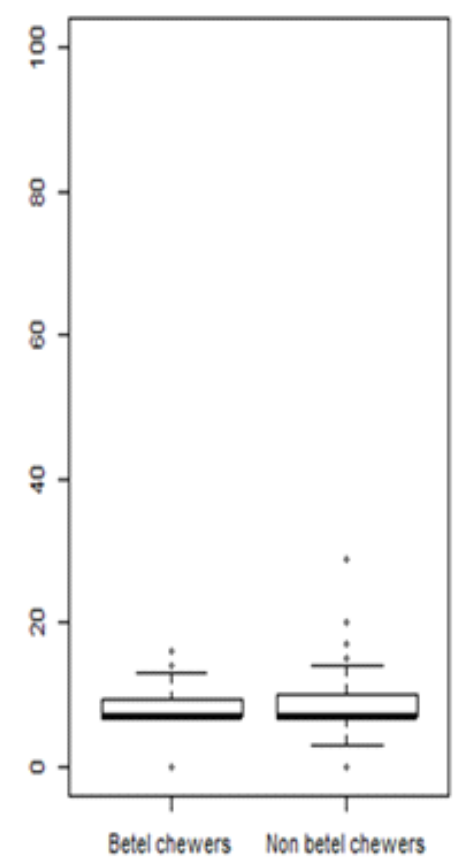

b) Total Positive socore

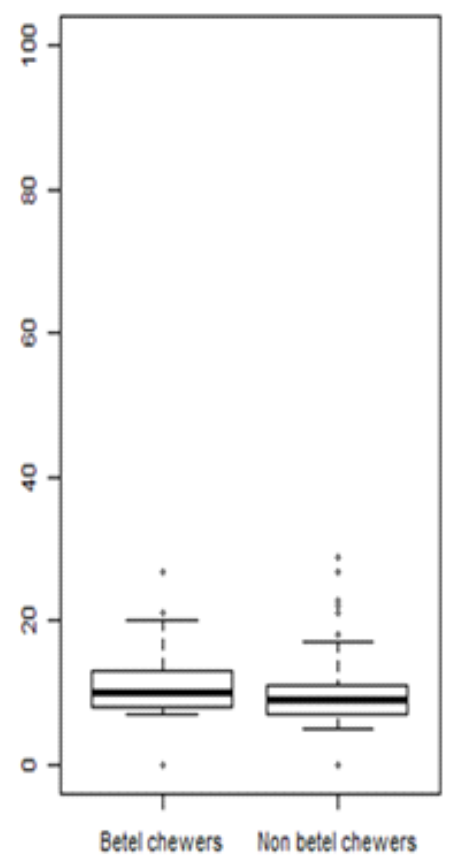

c) Total PANSS

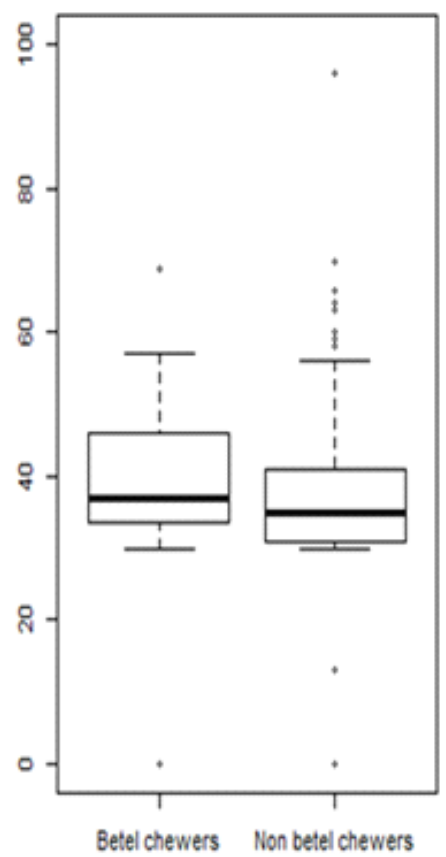

Figure 1. Distribution of a) total negative score, b) total positive score and c) total PANSS score between betel chewers and non-betel chewers among schizophrenia patients.

Table 2. PANSS score, EPSE and anticholinergic side effects among patients with schizophrenia and use of betel quid

\begin{tabular}{|c|c|c|c|}
\hline & $\begin{array}{c}\text { Patients with } \\
\text { schizophrenia who } \\
\text { chewed betel quid } \\
(n=47)\end{array}$ & $\begin{array}{c}\text { Patients with } \\
\text { schizophrenia who } \\
\text { didn't chew betel } \\
(n=104)\end{array}$ & $P$ value \\
\hline Mean age (SD) & $46.0(13.9)$ & $45.2(13.0)$ & 0.737 \\
\hline Males & $38(80.9)$ & $34(32.7)$ & $<0.001$ \\
\hline Total PANSS score & $38.1(13.3)$ & $36.6(14.2)$ & 0.545 \\
\hline Total positive score & $10.9(5.3)$ & $9.7(5.0)$ & 0.222 \\
\hline High consumption (10+quids/day) & $15.5(10.1)$ & & 0.392 \\
\hline Low consumption (>10 quids/day) & $10.4(4.6)$ & & \\
\hline Total negative score & $8.4(3.3)$ & $8.4(3.8)$ & 0.907 \\
\hline High consumption (10+quids/day) & $7.7(1.0)$ & & 0.217 \\
\hline Low consumption ( $>10$ quids/day) & $8.4(3.4)$ & & \\
\hline EPSE & $1.6(1.9)$ & $1.0(1.7)$ & 0.088 \\
\hline High consumption (10+quids/day) & $1.2(1.2)$ & & 0.593 \\
\hline Low consumption(>10 quids/day) & $1.6(2.0)$ & & \\
\hline Anticholinergic side effects & $3.0(2.2)$ & $2.1(2.3)$ & 0.040 \\
\hline
\end{tabular}




\begin{tabular}{|c|c|c|c|c|c|}
\hline Dependent variable & $\begin{array}{c}\text { Independent } \\
\text { variables }\end{array}$ & Estimate & $\begin{array}{l}\text { Standard } \\
\text { error }\end{array}$ & $\mathrm{T}$ value & $P$ value \\
\hline EPSE & $\begin{array}{l}\text { Intercept } \\
\text { Age }\end{array}$ & $\begin{array}{l}0.096 \\
0.024\end{array}$ & $\begin{array}{l}0.519 \\
0.011\end{array}$ & $\begin{array}{l}0.185 \\
2.264\end{array}$ & $\begin{array}{l}0.853 \\
0.025\end{array}$ \\
\hline Anticholinergic SE & $\begin{array}{l}\text { Intercept } \\
\text { Female gender } \\
\text { Betel quid } \\
\text { chewing }\end{array}$ & $\begin{array}{l}1.357 \\
1.170 \\
1.3766\end{array}$ & $\begin{array}{l}0.347 \\
0.403 \\
0.4343\end{array}$ & $\begin{array}{l}3.910 \\
2.906 \\
3.170\end{array}$ & $\begin{array}{l}<0.001 \\
0.004 \\
0.002\end{array}$ \\
\hline
\end{tabular}

\section{Discussion}

The prevalence of betel quid in the total study population was $20.9 \%$. The prevalence of betel chewing among patients with and without mental illness was similar. In a previous study conducted among the general population in Sri Lanka the prevalence of betel chewing was reported as $17.6 \%$ in rural and $1.7 \%$ in urban areas, whereas another study reported that nearly $53 \%$ of the rural community in Sri Lanka chewed betel, specially estate workers, labourers, and drivers $(7,17)$. De Silva et. al., reported that betel chewing was more prevalent among older people in Sri Lanka (7).

We could not elicit a significant difference in betel chewing among different age groups. However, we found that betel chewing was significantly more prevalent among males and also among those who had a lower level of education. We did not find a significant association between betel quid chewing and economic status of the patient.

Arecoline, the major alkaloid released from areca nut, which is one of the constituents of betel quid, is reported to function as a partial muscarinic agonist and has been hypothesized to have beneficial effects on both positive and negative symptoms of schizophrenia (11). Sullivan et al. reported that patients with schizophrenia who chewed betel quid had lower scores on both the negative and positive scales of the PANSS, but there were no differences in extrapyramidal symptoms or tardive dyskinesia $(11,15)$. A review done by Coppola reported that males with a high consumption of betel quid had significantly lower positive symptoms compared to low consumers or non-betel users (18). However, a study done in Nepal among patients with schizophrenia did not find a significant difference in the PANSS scores among betel chewers and non-chewers (19). Deahl described two patients with chronic schizophrenia who were on depot antipsychotics, who developed severe extrapyramidal symptoms in the context of a period of heavy betel nut consumption (20). Deahl had hypothesized that this is due to the antagonistic effect of arecoline (active ingredient of area) on the anticholinergic agent, procyclidine (20).

In this study, we did not find a significant difference in the positive scores of PANSS, in patients with schizophrenia, who did and did not chew betel quid. Similarly, among our study participants, betel quid chewing did not have a significant impact on the extra pyramidal symptoms, in patients with schizophrenia. However occurrence of anticholinergic side effects showed a significant association with gender and betel chewing.

\section{Study Limitations}

We did not have access to the patents' clinical records and most of the patients were not aware of the names or doses of the psychotropic medication they were on; therefore, we could not investigate the effects of psychotropics on the PANSS as a confounding factor, which is a limitation. Betel quid chewed by some of the participants of our study sample contained tobacco as an ingredient, which may have an effect on the symptoms of schizophrenia. This and other psychoactive substances which some of the patients used may have had an effect on the PANSS score.

\section{Conclusions}

There was no significant difference in the prevalence in betel quid chewing between those with and without a 
mental illness. There was no association between betel quid use and symptoms of schizophrenia or extra pyramidal side effects. The possible effect of betel quid chewing on symptoms of schizophrenia and side-effects of psychotropic medication should be explored further, preferably in a longitudinal study. This is particularly important in Sri Lanka, given the relatively high prevalence of betel quid use among patients with schizophrenia in this country.

\section{Acknowledgments}

PANSS was purchased through a research grant obtained by the co-principal investigator ( $\mathrm{AH}$ ) from the World Health Organization. Permission was granted by the publisher for the use of LUNCERS.

\section{Conflicts of interest}

None declared.

\section{Funding}

This research project was supported by a World Health Organization Research Grant.

Amila Isuru, University Psychiatry Unit, North Colombo Teaching Hospital, Ragama, Sri Lanka

Dileepa Ediriweera, Centre for Health Informatics, Biostatistics and Epidemiology, Faculty of Medicine, Faculty of Medicine, University of Kelaniya, Sri Lanka

Arunasalam Pathmeswaran, Department of Public Health, Faculty of Medicine, University of Kelaniya, Sri Lanka

A Embuldeniya, H Narammalage, Department of Psychiatry, Faculty of Medicine, University of Kelaniya, Sri Lanka

Saman Warnakulasuriya, King's College London, and World Health Organization Collaborating Centre for Oral Cancer, UK

KALA Kuruppuarachchi, Aruni Hapangama, Department of Psychiatry, Faculty of Medicine, University of Kelaniya, Sri Lanka

Corresponding author: Amila Isuru

Email: amila.isuru23@gmail.com

http://orcid.org/0000-0003-3113-1209

\section{References}

1. Croucher R. Islam S. Socio-economic aspects of areca nut use. Addiction Biology. 2002; 7(1) 139-46.

2. Gupta PC, Warnakulasuriya S. Global epidemiology of areca nut usage. Addiction Biology. 2002; 7(1) 77-83.

3. Chiba I, Muthumala M, Yamazaki Y, Zaman A, Lizuka T, Amemiya A. Characteristics of mutations in the gene of oral squamous-cell carcinomas associated with betel-quid chewing in Sri Lanka. International Journal of Cancer. 1999; 80(3): 486-7.

4. Ysao J, Chilton JI, Callaghan, P. A survey of betel nut chewing in Palau. ISLA: A Journal of Micronesian Studies. 1995; 42: 244-55.

5. Abayaratna S, Krishnarasa K. National oral health survey: Sri Lanka, 1994/95: Ministry of Health, Colombo, Sri Lanka; 1997. http://www.moh.gov.lk

6. Warnakulasuriya S. Smoking And Chewing Habits In Sri Lanka: Implications For Oral Cancer And Pre cancer, In Gupta PC, Hamner JE, Murtip. R, (Eds), Control Of Tobacco Related Cancers And Other Diseases, Oxford University Press, Oxford. 1992; 113-8.

7. De Silva V, Hanwella D, Gunawardena N. Prevalence of Betel Chewing Among Males in Colombo and Polonnaruwa Districts. Journal of the College of Community Physicians of Sri Lanka. 2011; 14(1): 20.

8. Chandra P, Carey M, Carey K, Jairam K. Prevalence and correlates of areca nut use among psychiatric patients in India. Drug and Alcohol Dependence. 2003; 69(3): 311-16.

9. Kuruppuarachchi K, Williams S. Betel use and schizophrenia. British Journal of Psychiatry. 2003; 182(5): 455-455.

10. Burton-Bradley B. Arecaidinism: Betel Chewing in Transcultural Perspective. The Canadian Journal of Psychiatry. 1979; 24(5): 481-88.

11. Sullivan R, Andres S, Otto C, Miles W, Kydd R. The Effects of an Indigenous Muscarinic Drug, Betel Nut (Areca catechu), on the Symptoms of Schizophrenia: A Longitudinal Study in Palau, Micronesia. American Journal of Psychiatry. 2007; 164(4): 670-3.

12. Sullivan R, Allen J, Otto C, Tiobech J, Nero K. Effects of chewing betel nut (Areca catechu) on the symptoms of people with schizophrenia in Palau, Micronesia. British Journal of Psychiatry. 2000; 177(2): 174-8.

13. Isuru A, Rajasuriya M. Tobacco smoking and schizophrenia: re-examining the evidence. BJPsych Advances. 2019; 25(6): 363-72.

14. The ICD-10 Classification of Mental and Behavioural Disorders: Clinical Descriptions and Diagnostic Guidelines by World Health Organization. Published by WHO Geneva. 
15. Kay S, Fiszbein A, Opler L. The Positive and Negative Syndrome Scale (PANSS) for Schizophrenia. Schizophrenia Bulletin. 1987; 13(2): 261-76.

16. Day J, Wood G, Dewey M, Bentall R. A Self-Rating Scale for Measuring Neuroleptic Side-Effects. British Journal of Psychiatry. 1995; 166(5): 650-3.

17. Siriwardana K. $90 \%$ oral cancer caused by chewing betel. Ceylon Today. 2012: 172.

18. Oppola M, Mondola R. Potential action of betel alkaloids on positive and negative symptoms of schizophrenia: A review. Nordic Journal of Psychiatry. 2011; 66(2): 73-8.

19. Bales A, Peterson MJ, Ojha S, et al. Associations between betel nut (Areca catechu) and symptoms of schizophrenia among patients in Nepal: A longitudinal study. Psychiatry Research 2009; 30169(3): 203-11.

20. Deahl M. Betel nut-induced extrapyramidal syndrome: an unusual drug interaction. Mov Disord 2009; 4(4): 330-2. 